RESEARCH REPORT

\title{
Environmental inequality and circulatory disease mortality gradients
}

\author{
Murray M Finkelstein, Michael Jerrett, Malcolm R Sears
}

J Epidemiol Community Health 2005;59:481-487. doi: 10.1136/jech.2004.026203

See end of article for authors' affiliations ....................

Correspondence to: Dr M Finkelstein, Family Medicine Centre, Suite 413, Mt Sinai Hospital Toronto, Ontario, Canada M5G 1X5; murray.finkelstein@ utoronto.ca

Accepted for publication 3 November 2004

\begin{abstract}
Study objective: Studies in Europe and North America have reported that living in a disadvantaged neighbourhood is associated with an increased incidence of coronary heart disease. The aim of this study was to test the hypotheses that exposure to traffic and air pollution might account for some of the socioeconomic differences in mortality rates in a city where residents are covered by universal health insurance.

Design: Cohort mortality study. Individual postal codes used to derive: (1) socioeconomic status from census data; (2) mean air pollution levels from interpolation between governmental monitoring stations; (3) proximity to traffic from the geographical information system. Analysis conducted with Cox proportional hazards models.

Setting: Hamilton Census Metropolitan Area, Ontario, Canada, on the western tip of Lake Ontario (population about 480 000).

Participants: 5228 people, aged 40 years or more, identified from register of lung function laboratory at an academic respirology clinic between 1985 and 1999.

Main results: Circulatory disease (cardiovascular and stroke) mortality rates were related to measures of neighbourhood deprivation. Circulatory disease mortality rates were also associated with indices of long term ambient pollution at the subjects' residences (relative risk 1.06, 1.00 to 1.13) and with proximity to traffic (relative risk 1.40, 1.08 to 1.81). Subjects in more deprived neighbourhoods had greater exposure to ambient particulate and gaseous pollutants and to traffic.

Conclusions: At least some of the observed social gradients in circulatory mortality arise from inequalities in environmental exposure to background and traffic air pollutants.
\end{abstract}

$\mathrm{S}$ tudies in the $\mathrm{USA}^{1}$ and Europe ${ }^{2-5}$ have reported that living in a disadvantaged neighbourhood is associated with an increased incidence of coronary heart disease. This relation persists even after controlling for individual level risk factors including smoking, physical activity, diet, serum lipids, body mass index (BMI), hypertension, and diabetes. ${ }^{1}$ Marmot ${ }^{6}$ asked whether health status is worse in poor areas because poor people live there, or are there features of the environment that might predict ill health over and above the socioeconomic characteristics of the residents? He concluded that something in addition to socioeconomic differences in these risk factors must be responsible for the differences in the incidence of heart disease.

The extent to which social circumstances influence disease pathways through exposure to physical, chemical, and biological agents is uncertain. Living in a disadvantaged community may be bad for health because of lack of access to amenities, which in turn may affect access to healthful foods, to opportunities for physical activity, and to medical and other services. In addition, insecurity, fear of crime, suffering from the effects of a low position in the socioeconomic hierarchy, and lack of social support are all features of disadvantaged communities that might increase inequalities in health. ${ }^{6}$ Diez Roux ${ }^{7}$ suggested that, although research is scant, noise, air pollution, and traffic might be features of neighbourhood physical environments that might contribute to area differences in cardiovascular risk.

The aim of this study was to test the hypotheses that exposure to traffic and air pollution might account for some of the socioeconomic differences in mortality rates in a city where residents are covered by universal health insurance.

\section{METHODS}

\section{Study site description}

The study is situated in the city of Hamilton, Ontario, Canada, located on the western tip of Lake Ontario, midway between Toronto, Ontario and Buffalo, New York. The population is 480000 . Hamilton has a mixed economy including several large integrated steel making operations. These plants produce spatially concentrated pollution emissions in the north east end near the industrial core.

\section{Study subjects and follow up}

The subjects are residents of Hamilton and Burlington, Ontario, who performed pulmonary function testing (PFT) at an academic clinic between 1985 and 1999, whether referred for specialist assessment or for spirometry only. Subjects entered follow up on 1 January 1992, the year in which the Province of Ontario introduced a personal health insurance number (HIN), or the date of PFT testing, whichever was later. Mortality was ascertained by probabilistic linkage to the Ontario Mortality Registry, 1992-2001 using full name, sex, birth date, and residence city as the primary linking variables. Because few subjects under 40 years of age died, this study was restricted to age 40 or older. Subjects diagnosed with cancer either before, or within

Abbreviations: SES, socioeconomic status; GIS, geographical information system; BMI, body mass index; HIN, health insurance number; PFT, pulmonary function testing; FVC, forced vital capacity; FEV, forced expiratory volume; TSP, total suspended particulate; DI, deprivation index; EA, enumeration area 
Table 1 Distribution of demographic, clinical, socioeconomic, and pollution variables by deprivation quartile (Q)

\begin{tabular}{|c|c|c|c|c|}
\hline & Lowest deprivation quartile & Deprivation Q2 & Deprivation Q3 & Highest deprivation quartile \\
\hline Age & $(48.9,58.3,68.1)^{*}$ & $(50.9,60.2,71.4)$ & $(50.9,62.0,71.4)$ & $(51.2,63.6,71.6)$ \\
\hline Female & $54 \%$ & $56 \%$ & $57 \%$ & $56 \%$ \\
\hline & $(24.4,27.6,31.2)$ & $(24.6,27.7,31.7)$ & $(24.2,27.7,31.6)$ & $(24.3,27.9,32.2)$ \\
\hline & $(75,89,102)$ & $(73,88,102)$ & $(68,84,98)$ & $(65,82,96)$ \\
\hline $\begin{array}{l}\mathrm{FEV}_{1}(\% \text { Predicted) } \\
\text { Diagnosed with asthma }\end{array}$ & $\begin{array}{l}(63,83,98) \\
12 \%\end{array}$ & $\begin{array}{l}(57,81,97) \\
10 \%\end{array}$ & $\begin{array}{l}(52,75,94) \\
10 \%\end{array}$ & $\begin{array}{l}(48,72,90) \\
10 \%\end{array}$ \\
\hline $\begin{array}{l}\text { Diagnosed with chronic obstructive } \\
\text { pulmonary disease }\end{array}$ & $31 \%$ & $36 \%$ & $42 \%$ & $47 \%$ \\
\hline Diagnosed with IHD & $28 \%$ & $32 \%$ & $34 \%$ & $35 \%$ \\
\hline Diagnosed with diabetes & $13 \%$ & $16 \%$ & $18 \%$ & $18 \%$ \\
\hline $\begin{array}{l}\text { Annualised per capita Physician } \\
\text { expenditures }(\$)\end{array}$ & $(450,770,1400)$ & $(490,870,1400)$ & $(500,870,1400)$ & $(520,920,1500)$ \\
\hline $\begin{array}{l}\text { Neighbourhood household income } \\
\text { (thousands \$) }\end{array}$ & $(61,70,81)$ & $(48,53,58)$ & $(37,41,44)$ & $(25,31,33)$ \\
\hline $\begin{array}{l}\text { Neighbourhood residents with less than } \\
\text { high school education (\%) }\end{array}$ & $(16,18,22)$ & $(21,24,26)$ & $(23,27,30)$ & $(26,32,36)$ \\
\hline $\begin{array}{l}\text { Neighbourhood male unemploymentrate(\%) } \\
\operatorname{TSP}\left(\mu \mathrm{g} / \mathrm{m}^{3}\right)\end{array}$ & $\begin{array}{l}(2.4,4.5,6.9) \\
(30,37,42)\end{array}$ & $\begin{array}{l}(4.4,7.1,10.0) \\
(32,37,42)\end{array}$ & $\begin{array}{l}(7.3,10.3,13.8) \\
(37,43,48)\end{array}$ & $\begin{array}{l}(12.2,17.4,21.6) \\
(41,47,55)\end{array}$ \\
\hline $\mathrm{SO}_{2}(\mathrm{ppb})$ & $(4.22,4.24,4.26)$ & $(4.20,4.26,4.78)$ & $(4.48,5.17,5.70)$ & $(4.96,5.78,6.66)$ \\
\hline $\begin{array}{l}\text { Pollution indext } \\
\text { Exposed to traffic pollution }\end{array}$ & $\begin{array}{l}(-1.9,-1.0,-0.5) \\
12 \%\end{array}$ & $\begin{array}{l}(-1.8,-1.1,-0.2) \\
13 \%\end{array}$ & $\begin{array}{l}(-0.7,0.3,1.4) \\
20 \%\end{array}$ & $\begin{array}{l}(-0.1,1.5,3.3) \\
27 \%\end{array}$ \\
\hline
\end{tabular}

45 days, of the initial visit were excluded because their survival pattern would be atypical, leaving 5228 subjects.

Information abstracted from the laboratory database included the subjects' HIN, postal code, BMI, and PFT measures including forced vital capacity (FVC) and forced expiratory volume in one second $\left(\mathrm{FEV}_{1}\right)$. All subjects were covered by the universal Ontario Health Insurance Plan (OHIP). In accordance with the Canada Health Act, the Ontario Health Insurance Program is a portable, universally available, publicly funded, free access insurance system covering most expenses related to hospitals and associated facilities, long term care, mental health services, ambulatory and emergency services, and other primary care services. Dental care and drug benefits are not included. Linkage to OHIP was used to classify underlying respiratory disease status using diagnostic codes submitted by specialist physicians. Subjects were also classified with diabetes (ICD9: 250) or chronic ischaemic heart disease (IHD) (ICD9: 412-414) if the diagnosis appeared in two or more claims submissions by a general practitioner, one claim submission by a specialist, or in any hospitalisation. This algorithm has been validated for diabetes diagnoses in Ontario. ${ }^{8}$ As an indicator of use of medical services, the cost of medical services billed to OHIP for each subject, by physicians, was summed from the date of entry. A length adjusted cost was computed by dividing the total cost by the length of follow up.

\section{Estimation of a deprivation index}

Personal socioeconomic data were not available. The enumeration area (EA), with an average population of 750, is the smallest geographical unit for which census data are available in Canada. The census of 1996 was used to estimate median household income, the proportion of high school graduates, and the local unemployment rate by overlay of EA data onto subjects' six character postal codes. We used principal components ${ }^{9}$ to generate a deprivation index, $\mathrm{DI}=(-0.66 \times \log ($ income $)+0.55 \times$ unemployment rate + $0.51 \times$ proportion of residents who did not complete high school) for each subject. An index of this type was associated with mortality rates in Quebec, a neighbouring province. ${ }^{10}$

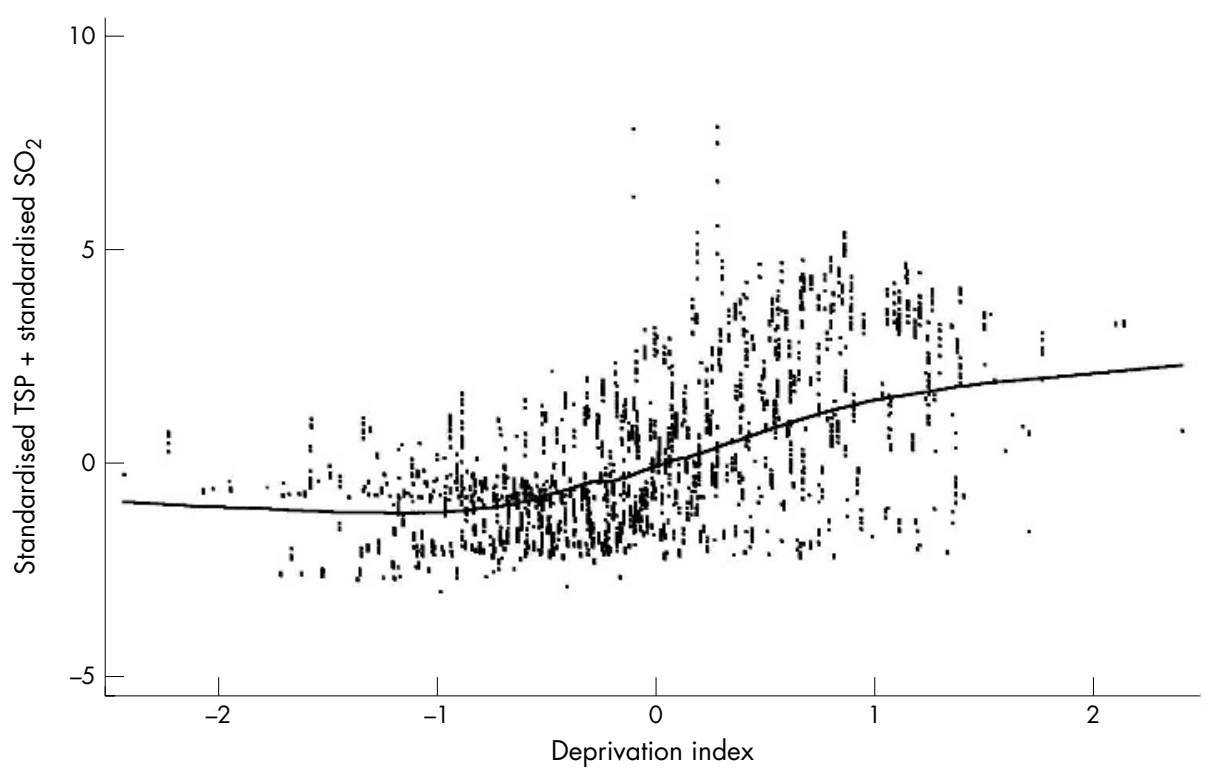

Figure 1 Association between the pollution index (standardised TSP + standardised $\mathrm{SO}_{2}$ ) and the deprivation index among cohort subjects. The line is a Lowess smoother. 


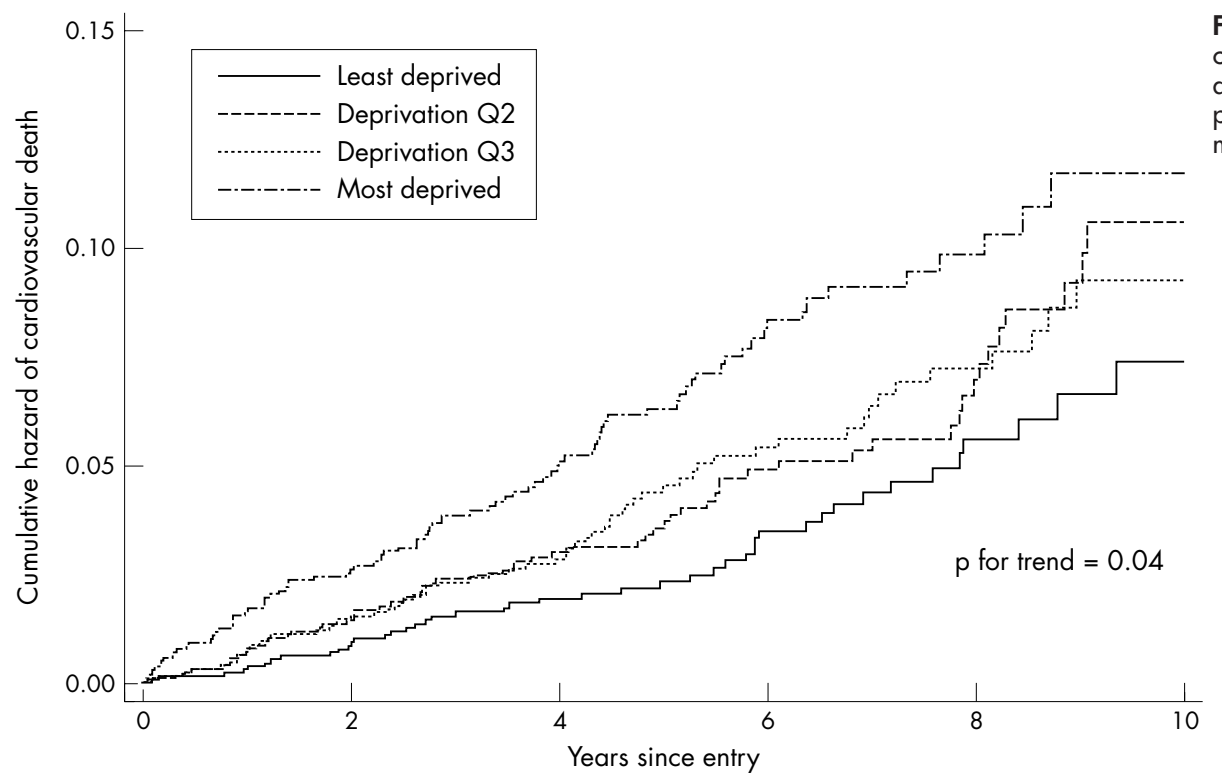

Figure 2 Cumulative hazard of cardiovascular mortality in relation to quartiles of the deprivation index. The $p$ value for trend comes from the full multivariate Cox model.

The DI was normally distributed with a mean of 0 and standard deviation of 0.8 . Higher scores on the DI show a less favourable combination of income, education, and employment.

\section{Estimation of air pollution and traffic exposures}

The Arcview geographical information system (GIS) was used to estimate mean air pollutant levels at the subjects' residences (ESRI, Redlands, CA). The pollution data available were measurements of total suspended particulate (TSP; 1992-94), sampled every sixth day, and continuous hourly measurements of $\mathrm{SO}_{2}$ (1993-95), averaged as daily values. These time segments represent the periods of maximal extent of the Ontario Ministry of Environment (MOE) monitoring network in the Hamilton Urban Area. As we were interested in long term exposures, these data were used to compute annual averages. We expect the three year period will approximate long term exposure patterns. Gradients for both pollutants are known to decrease outward from the heavy industrial zone in north central and north east Hamilton, partly driven by prevailing winds, topographical elevation on the Niagara Escarpment, and temperature inversions that trap pollutants near ground level. ${ }^{11}$ Although absolute levels of these pollutants may fluctuate slightly through time, this strong gradient of higher levels away from the industrial core, which operated for the entire study period, persists over time. To model the pollution concentration gradients more accurately throughout peripheral areas, data from MOE stations in neighbouring municipalities were also used. The inclusion of these sites increased the total number of stations used in modelling to 19 for $\mathrm{SO}_{2}$, and 29 for TSP. Universal kriging ${ }^{11}$ was used for spatial interpolation between monitoring stations. GS+ 2.1 geostatistical software (Gamma Design Software, Plainwell, MI) was used to generate the interpolation estimates. The three year means were applied to the entire observation period, 1992 to 2001 . Figure 4 shows the distribution of the residence locations of the study subjects and the mean TSP levels assigned to their residences.

Because neighbourhood levels of TSP and $\mathrm{SO}_{2}$ were correlated (Spearman's $\rho=0.56, p<0.001$ ) we also created a "pollution index" that was the sum of the standardised scores, $(x-\mu) / \sigma$, for each of the pollutants.

We used the same indicator of traffic related pollution as investigators in the Netherlands. ${ }^{12}$ Subjects residing within 50 metres of a major urban road or within 100 metres from a highway were considered exposed. Because Hamilton is an

Table 2 Relative risk of death in relation to the deprivation and pollution indices and the traffic exposure indicator. All proportional hazards models were adjusted for age, sex, lung function, BMI, and diagnoses of chronic ischaemic heart disease, obstructive lung disease, and diabetes. In the univariate models, the exposure variables were included separately

\begin{tabular}{llll}
\hline & $\begin{array}{l}\text { Cardiovascular mortality } \\
\text { ICD9: } \mathbf{4 0 1 - 4 2 8}(\mathbf{n = 2 5 2 )}\end{array}$ & $\begin{array}{l}\text { Cerebrovascular mortality } \\
\text { ICD9 430-438 (n=58) }\end{array}$ & $\begin{array}{l}\text { Respiratory mortality } \\
\text { ICD9: 460-519 (n=232) }\end{array}$ \\
\hline $\begin{array}{l}\text { Univariate exposure models } \\
\begin{array}{l}\text { Deprivation index } \\
\text { Pollution index }\end{array}\end{array}$ & $1.15(1.03$ to 1.29$)$ & $1.15(0.82$ to 1.61$)$ & $0.98(0.83$ to 1.15$)$ \\
$\begin{array}{l}\text { Traffic indicator } \\
\text { Bivariate exposure models }\end{array}$ & $1.06(1.00$ to 1.13$)$ & $1.01(0.88$ to 1.16$)$ & $0.97(0.89$ to 1.05$)$ \\
$\begin{array}{l}\text { Deprivation index } \\
\text { Pollution index }\end{array}$ & $1.40(1.08$ to 1.81$)$ & $1.85(1.09$ to 3.14$)$ & $0.95(0.71$ to 1.26$)$ \\
& $1.12(0.98$ to 1.27$)$ & $1.18(0.83$ to 1.67$)$ & $1.01(0.87$ to 1.19$)$ \\
$\begin{array}{l}\text { Deprivation index } \\
\text { Traffic indicator }\end{array}$ & $1.04(0.97$ to 1.11$)$ & $0.97(0.85$ to 1.12$)$ & $0.97(0.88$ to 1.05$)$ \\
$\begin{array}{l}\text { Trivariate exposure model } \\
\text { Deprivation index } \\
\text { Pollution index } \\
\text { Traffic indicator }\end{array}$ & $1.13(1.00$ to 1.27$)$ & $1.09(0.77$ to 1.56$)$ & $0.98(0.84$ to 1.16$)$ \\
\hline
\end{tabular}


Table 3 Relative risk of death in relation to the combined deprivation/pollution index and the traffic exposure indicator. All proportional hazards models were adjusted for age, sex, lung function, BMI, and diagnoses of chronic ischaemic heart disease, obstructive lung disease, and diabetes

\begin{tabular}{|c|c|c|c|}
\hline & $\begin{array}{l}\text { Cardiovascular mortality } \\
\text { ICD9: } 401-428(n=252)\end{array}$ & $\begin{array}{l}\text { Cerebrovascular mortality } \\
\text { ICD9: } 430-438(n=58)\end{array}$ & $\begin{array}{l}\text { Respiratory mortality } \\
\text { ICD9: } 460-519 \text { ( } n=232)\end{array}$ \\
\hline \multicolumn{4}{|l|}{ All subjects } \\
\hline Deprivation/pollution index & $1.05(1.01$ to 1.10$)$ & $1.02(0.91$ to 1.13$)$ & $0.98(0.92$ to 1.04$)$ \\
\hline $\begin{array}{l}\text { Traffic indicator } \\
\text { Subjects with obstructive lung disease }\end{array}$ & 1.38 (1.07 to 1.78$)$ & $1.84(1.09$ to 3.10$)$ & $0.96(0.72$ to 1.27$)$ \\
\hline Deprivation/pollution index & $1.03(0.97$ to 1.10$)$ & $1.02(0.91$ to 1.15$)$ & $0.97(0.91$ to 1.04$)$ \\
\hline $\begin{array}{l}\text { Traffic indicator } \\
\text { Subjects without obstructive lung disease }\end{array}$ & 1.41 (0.98 to 2.03$)$ & 2.16 (1.09 to 4.30$)$ & $0.98(0.71$ to 1.34$)$ \\
\hline Deprivation/pollution index & 1.09 (0.99 to 1.19$)$ & $1.00(0.87$ to 1.16$)$ & $1.03(0.91$ to 1.18$)$ \\
\hline Traffic indicator & $1.39(0.86$ to 2.27$)$ & $1.47(0.62$ to 3.46$)$ & $0.85(0.38$ to 1.90$)$ \\
\hline
\end{tabular}

older city, most of the study area has a stable transportation network throughout the period of study. One major new expressway was opened in 1996, roughly half way through follow up.

\section{Modelling of mortality relative risk modelling of mortality relative risk}

Mortality outcomes included: cardiovascular disease, ICD9 401-428; cerebrovascular disease, ICD9 430-438; and, respiratory disease, ICD9: 460-519. The Cox proportional hazards model ${ }^{13}$ was used to model mortality relative risk (RR). Standard errors were adjusted for clustering in census tracts. Deviations from the proportional hazards assumption were tested by introducing interactions of time with all covariates. Calculations were performed with Stata statistical software, version 8 .

\section{RESULTS}

Table 1 shows the distributions of demographic, clinical, socioeconomic, and pollution variables by quartile of the DI. Subjects in the more deprived neighbourhoods were older and their lung function measures were lower. BMI was similar across the deprivation quartiles. There was no relation between the diagnosis of asthma and deprivation $(p=0.71$ after adjustment for age and sex), but the prevalence of chronic obstructive pulmonary disease, ischaemic heart disease, and diabetes was strongly associated with deprivation $(\mathrm{p}<0.01)$. In this population covered by universal health insurance, annualised expenditures on physicians' services were significantly higher among subjects in more deprived neighbourhoods $(p=0.01$ for the relation between $\log$ (income) and deprivation index after adjustment for age and sex).

Particulate and gaseous pollution levels were higher in more deprived neighbourhoods $(\mathrm{p}<0.01$ for trend for both TSP and $\mathrm{SO}_{2}$ ), as was the percentage of subjects living near traffic. Figure 1 shows the pollution index plotted against the DI.

\section{Neighbourhood deprivation and mortality}

Figure 2 shows cumulative hazard curves ${ }^{13}$ for cardiovascular mortality in relation to deprivation quartiles. Table 2 shows the results of proportional hazards models. All were adjusted for age, sex, lung function, BMI and the square of BMI, and diagnoses of obstructive lung disease, chronic ischaemic heart disease, and diabetes. Preliminary models included TSP (relative risk: 1.07 (0.92 to 1.24)) and $\mathrm{SO}_{2}$ (relative risk: 1.07 $(0.95$ to 1.22$)$ ). As these variables were highly correlated, we decided to use the pollution index to address the policy issue of whether pollutants contribute to the socioeconomic

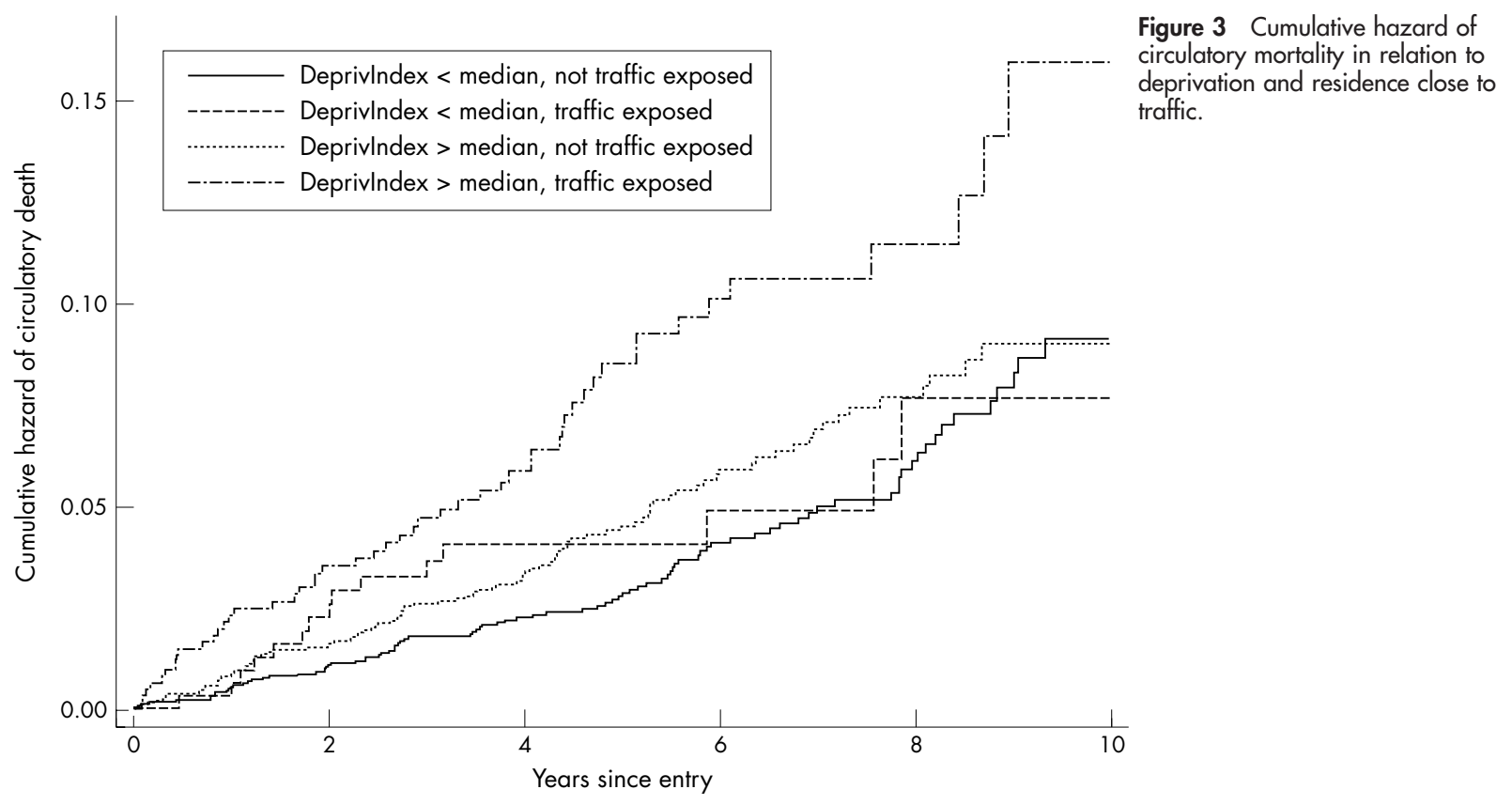


differences in circulatory mortality. Table 2 begins with univariate exposure models in which the deprivation and pollution indices and the traffic indicator were included individually in three separate models. All were significantly associated with cardiovascular mortality. The coefficient for the deprivation index was the same for cerebrovascular as for cardiovascular mortality, but the effect did not achieve significance for cerebrovascular mortality, possibly because of the substantially lower power. There was a significant association between the traffic indicator, but not the pollution index, and cerebrovascular mortality. There was no association between any of the exposure terms and respiratory mortality.

In the bivariate models, the DI was included together with the pollution index or traffic indicator. The traffic indicator remained significantly associated with both cardiovascular and cerebrovascular mortality. For cardiovascular mortality, in the model containing the deprivation and pollution indices, the effect of each risk factor was smaller than in the univariate models, because of collinearity, and each was no longer individually significant. The trivariate models included all three exposure variables simultaneously and the traffic indicator remained significantly associated with both cardiovascular and cerebrovascular mortality.

Because of the collinearity between the deprivation and pollution indices, we created a combined pollution/deprivation index $=$ sum $($ pollution index + standardised deprivation index). Table 3 shows the results of models including this pollution/deprivation index and the traffic indicator. For cardiovascular mortality, both the deprivation/pollution index and the traffic indicator were significantly associated with mortality.

\section{Effect modification by underlying disease status and deprivation}

The lower portion of table 3 gives results according to whether or not the subjects had been diagnosed with chronic obstructive pulmonary disease. The relative risks were similar and interaction analysis showed no significant differences in relation to lung disease status. A similar result (not shown) was that relative risks were similar for subjects with and without diagnoses of chronic ischaemic heart disease.

Figure 3 shows cumulative hazard curves for cardiovascular mortality in relation to the DI (dichotomised at the median) and traffic exposure. Because of small numbers the curves are unstable at longer follow up times, but it can be seen that the effect of traffic exposure was similar in both deprivation strata. In Cox models, there were no significant interactions between deprivation and traffic exposure or deprivation and the pollution index. There was thus no evidence of modification of the pollutant effects by neighbourhood deprivation.

\section{DISCUSSION}

In a cohort of subjects covered by universal health insurance, we have replicated the finding that circulatory disease (cardiovascular and stroke) mortality rates are related to measures of neighbourhood deprivation. Circulatory disease mortality rates were also associated with indices of ambient pollution at the subjects' residences and with residential

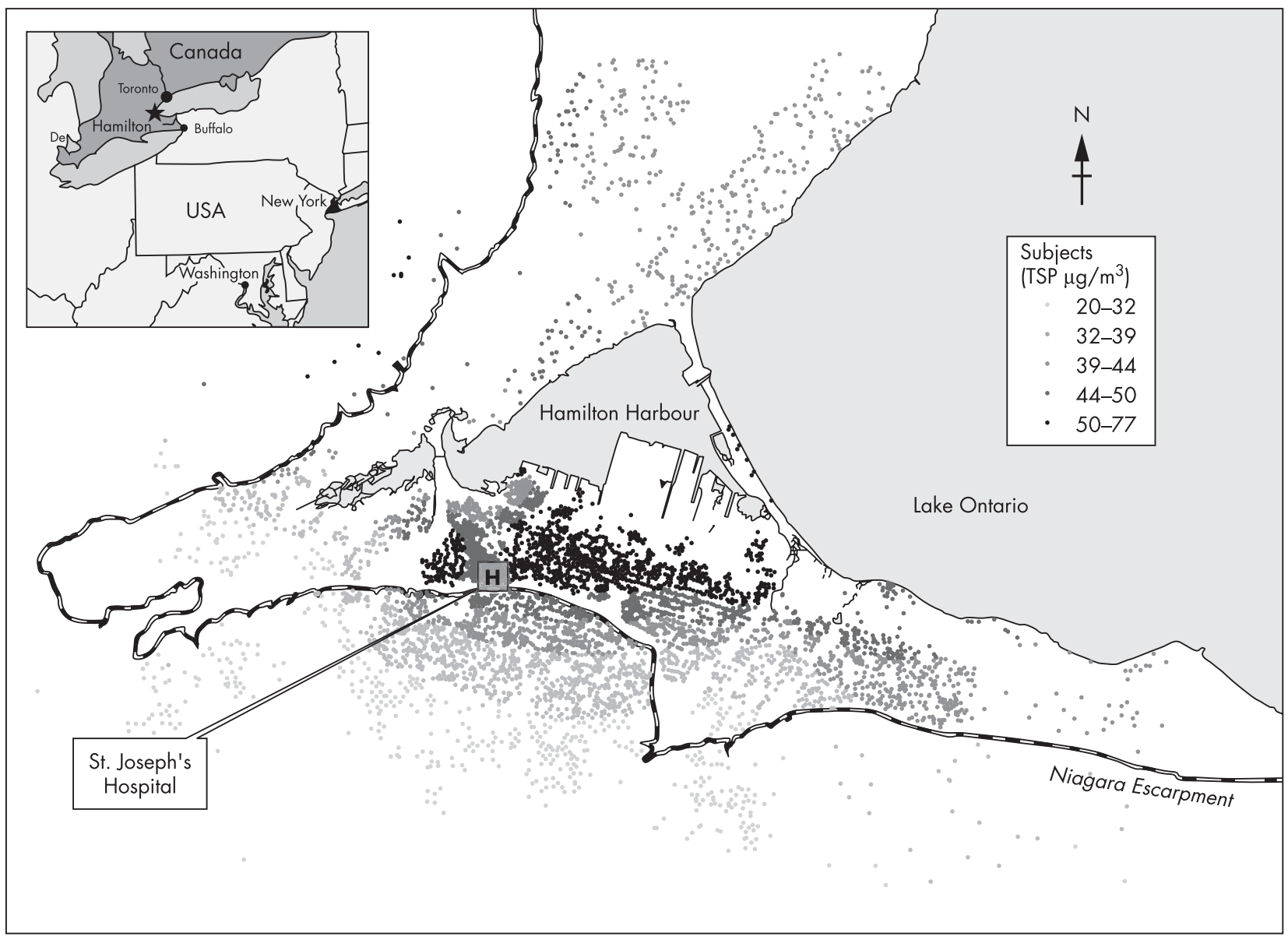

Figure 4 Residence locations, and mean TSP at residence locations, of study subjects. The distribution of $\mathrm{SO}_{2}$ exposures was qualitatively similar. 
proximity to traffic. As subjects in more deprived neighbourhoods had greater exposure to ambient particulate and gaseous pollutants and to traffic, we have confirmed the hypothesis that some part of the deprivation related circulatory disease mortality differential is related to differences in exposure to environmental pollutants. We found no evidence of effect modification by neighbourhood deprivation. That is, the effect of environmental exposures was the same in richer and poorer neighbourhoods.

A variety of explanations for the relation between circulatory disease mortality rates and neighbourhood socioeconomic status (SES) have been discussed. ${ }^{7}$ The levels of conventional risk factors for cardiovascular disease are generally more favourable in people with high SES, but adjusting for these reduces, but does not eliminate, observed differences in morbidity and mortality. ${ }^{14}$ Another explanation is differential access to medical care. The subjects of our study were all covered by universal health insurance that provides access to medical services without co-payment. We used physician billings as a proxy for access and use, and found that there was an inverse relation between the DI and expenditures on physicians' services. This is consistent with previous findings that use of physicians' services in Ontario is related to need and not to income. ${ }^{15}$ We conclude that there is no evidence that the relation between deprivation and circulatory mortality in this cohort is attributable to differential access to medical care.

We chose to include the diagnoses of diabetes, chronic lung disease, and chronic ischaemic heart disease as covariates in the Cox mortality models while recognising that chronic morbidity may also be associated with deprivation and with exposure to environmental pollutants. This was done because ours was not a random sample and these disease factors may have been influential in subjects entering the cohort. In fact, there was essentially no confounding because the coefficients of the exposure variables changed by less than $5 \%$ when the morbidity variables were excluded from the regression models.

Diez Roux ${ }^{7}$ suggested that noise, air pollution, and traffic might be features of neighbourhood physical environments that contribute to area differences in cardiovascular risk. There is scant research to support this hypothesis. Most time series and cohort studies of air pollution and cardiovascular disease have treated the city as the unit of analysis, and there has not been examination of intraurban variation. Exceptions include a cohort study of Norwegian men resident in Oslo ${ }^{16}$ and a Dutch cohort study. ${ }^{12}$ In the Norwegian study there was an association between ischaemic heart disease mortality and exposure to nitrogen oxides at the residence, but there was no relation between exposure and SES as measured by education or occupation. In the Dutch study there was a significant association between the traffic indicator and cardiopulmonary mortality, but "those living near a major road had slightly higher education, worked less frequently in blue-collar jobs, and smoked fewer cigarettes" - that is, they were of higher SES. Thus, the European studies do not support air pollution or traffic exposures as a contributor to the socioeconomic differential in circulatory disease mortality rates.

The SES of people living near major roads in North America may be different than in Europe. In California, ${ }^{17}$ subjects residing in census blocks among the lowest quartile of income were three times more likely to experience high traffic density than people in the highest income quartile. Another study in the South Coast Air Basin of California suggested that, on average, low income areas may experience higher ozone exposure than high income areas. ${ }^{18}$ A third study in California reported that a disproportionate number of students who attended schools close to major roads with

\section{Key points}

This paper is the first verification of the hypothesis that environmental factors, including exposure to vehicular traffic, play a part in the circulatory disease mortality differentials observed among neighbourhoods of different socioeconomic status.

very high traffic counts were economically disadvantaged. ${ }^{19}$ In our study, exposure to gaseous and particulate pollution was strongly related to deprivation. Hamilton is a city with a heavy industrial sector, so that socioeconomic differences in ambient air pollution exposures might be exaggerated. With respect to traffic, the proportion exposed increased from 12\% in the least deprived quartile to $27 \%$ in the most deprived. As seen in California, this is likely to be reflective of the North American socioeconomic context and is probably not strongly related to the extent of industrialisation.

A limitation of this study is that we do not, as yet, have measures of pollution exposure within the buffers close to traffic. Dutch investigators ${ }^{20}$ reported that daytime concentrations of $\mathrm{PM}_{10}$ were on average $30 \%$ higher near busy roads than at background locations, differing by $7-13 \mu \mathrm{g} / \mathrm{m}^{3}$. Another study reported that indoor and outdoor particulate concentrations were higher at homes located in high traffic intensity streets compared with homes in low traffic streets. ${ }^{21}$ The mean indoor concentration of $\mathrm{PM}_{2.5}$ in high traffic homes was $27 \mu \mathrm{g} / \mathrm{m}^{3}$ and was $12 \mu \mathrm{g} / \mathrm{m}^{3}$ in low traffic homes. In Massachusetts ${ }^{22}$ concentrations of fine particulate matter and particle bound polycyclic aromatic hydrocarbons were higher on roads reported to have heavy bus traffic. In New York, pavement measures of diesel exhaust particulate were correlated with the count of large trucks. ${ }^{23}$

Other variables, such as extreme weather, may differentially affect persons with low SES, and we have been unable to control for these factors in this analysis. In earlier studies of acute mortality, we assessed the impact of weather and found a significant association between both temperature and humidity and acute mortality. ${ }^{24}$ In this study, we were unable to assess the impact of urban heat islands because of data inconsistencies between suburban and inner city weather stations. It is possible that some of the mortality gradient in SES is partly attributable to extreme temperatures and the relative lack of air conditioning in deprived neighbourhoods. Future studies will attempt to use mesoscale meteorological models to overcome this limitation.

We found that cardiovascular and cerebrovascular mortality were associated with traffic exposure, but that respiratory mortality was not. This finding of association between air pollution and circulatory, but not respiratory mortality, is

\section{Policy implications}

- Some of the socioeconomic status gradient in cardiovascular disease arises from environmental inequality in air pollution exposures

- Policies and programmes aimed at improving air quality may therefore help to reduce health disparities in cardiovascular morbidity and mortality

- Policymakers may have to target environmental protection programmes to unprivileged neighbourhoods where high pollution and highly susceptible people share the same geographical space 
consistent with those of other North American cohort studies. ${ }^{25}{ }^{26}$ A variety of mechanisms have been proposed for the increase in cardiovascular risk attributed to particulate exposure. Inhaled particles could lead to acute exacerbation of cardiovascular disease through pulmonary inflammation triggering systemic hypercoagulability. ${ }^{27}$ Increases in plasma viscosity ${ }^{28}$ and $C$ reactive protein ${ }^{29}$ were found in randomly selected healthy adults after episodes of high particulate air pollution. Increased heart rate, ${ }^{3031}$ decreased heart rate variability, ${ }^{32-34}$ and increased risk of implanted cardioverter defibrillator discharges ${ }^{35}$ associated with episodes of particulate air pollution point to an autonomic nervous system response.

In our cohort, respiratory mortality was not associated with deprivation despite the variation of smoking prevalence with SES in Canada. ${ }^{36}$ We believe that the socioeconomic differential in smoking status was reduced in our cohort because subjects were referred for lung function testing. The more affluent subjects in our cohort were thus probably more likely to be smokers than were other Canadians of similar SES.

Another limitation is that we did not have individual information about education, occupation, or habits such as alcohol consumption or smoking. We were thus unable to account for the association between deprivation and an adverse risk factor profile, as were some previous investigators. ${ }^{1}$ The most important of these missing variables for cardiopulmonary mortality is cigarette smoking. The absence of association between respiratory mortality and the pollution index or traffic indicator suggests that smoking did not confound the associations of these exposures with circulatory mortality either.

Information was not available about change of residence (and consequent change in exposure) during the observation period. Misclassification because of residence change is likely to be non-differential with respect to the traffic indicator, resulting in underestimation of the mortality risk attributable to residence close to traffic.

Although our cohort was a sample of subjects attending for lung function testing and not a random sample, we believe that our results are generalisable, certainly within North America. The observed associations between pollutant and traffic exposures and circulatory mortality are consistent with the findings of other cohort studies, ${ }^{126}$ and the association between environmental exposures and deprivation is probably common in North America, if not in Europe. These findings have implications for regulatory and environmental policy, including measures to reduce emissions from vehicles and to encourage the use of public transportation and walking in cities.

\footnotetext{
Authors' affiliations

M M Finkelstein, Program in Occupational Health and Environmental Medicine and Institute of Environment and Health, McMaster University, Toronto, Canada

M Jerrett, School of Geography and Geology, Health Studies Program and Institute of Environment and Health, McMaster University

M R Sears, Department of Medicine, McMaster University

Funding: this research was supported by grants from the Toxic Substances Research Initiative of Health Canda and from the Canadian Institutes for Health Research.

Conflicts of interest: none declared.

Ethics approval: this study was approved by the research ethics board at St Joseph's HealthCare, Hamilton.

\section{REFERENCES}

1 Diez Roux AV, Merkin SS, Arnett D, et al. Neighborhood of residence and incidence of coronary heart disease. N Engl J Med 2001;345:99-106.
}

2 Sundquist K, Winkleby $M$, Ahlen $\mathrm{H}$, et al. Neighborhood socioeconomic environment and incidence of coronary heart disease: a follow-up study of 25,319 women and men in Sweden. Am J Epidemiol 2004;159:655-62.

3 Andersen I, Osler M, Petersen L, et al. Income and risk of ischaemic heart disease in men and women in a Nordic welfare country. Int J Epidemiol 2003;32:367-74.

4 Kolegard SM, Diderichsen F, Reuterwall C, et al. Socioeconomic context in area of living and risk of myocardial infarction: results from Stockholm heart epidemiology program (SHEEP). J Epidemiol Community Health 2002;56:29-35.

5 Smith GD, Hart C, Watt G, et al. Individual social class, area-based deprivation, cardiovascular disease risk factors, and mortality: the Renfrew and Paisley study. J Epidemiol Community Health 1998;52:399-405.

6 Marmot M. Inequalities in health. N Eng J Med 2001;345:134-6.

7 Diez Roux AV. Residential environments and cardiovascular risk. J Urban Health 2003;80:569-89.

8 Hux JE, Ivis F, Flintoft V, et al. Diabetes in Ontario: determination of prevalence and incidence using a validated administrative data algorithm. Diabetes Care 2002;25:512-16.

9 Dunteman GH. Principal components analysis. Newbury Park: Sage, 1989.

10 Pampalon R, Raymond G. A deprivation index for health and welfare planning in Quebec. Chronic Dis Can 2000;21:104-13.

11 Burrough PA, McDonnell RA. Principles of geographical information systems. New York: Oxford University Press, 1998.

12 Hoek G, Brunekreef B, Goldbohm S, et al. Association between mortality and indicators of traffic-related air pollution in the Netherlands: a cohort study. Lancet 2002;360:1203-9.

13 Hosmer DW, Lemeshow S. Applied survival analysis. New York: Wiley, 1999.

14 Lynch JW, Kaplan GA, Cohen RD, et al. Do cardiovascular risk factors explain the relation between socioeconomic status, risk of all-cause mortality, cardiovascular mortality, and acute myocardial infarction? Am J Epidemiol 1996; 144:934-42.

15 Finkelstein MM. Do factors other than need determine utilization of physicians' services in Ontario? Can Med Assoc J 2001;165:565-70.

16 Nafstad P, Haheim LL, Wisloff T, et al. Urban air pollution and mortality in a cohort of norwegian men. Environ Health Perspect 2004; 112:610-15.

17 Gunier RB, Hertz A, Von Behren J, et al. Traffic density in California: Socioeconomic and ethnic differences among potentially exposed children. $J$ Expo Anal Environ Epidemiol 2003;13:240-6.

18 Korc ME. A socioeconomic assessment of human exposure to ozone in the South Coast Air Basin of California. J Air Waste Manag Assoc 1996;46:547-57.

19 Green RS, Smorodinsky S, Kim JJ, et al. Proximity of California public schools to busy roads. Environ Health Perspect 2004;1 12:61-6.

20 Janssen NA, van Mansom DF, van der Jagt K, et al. Mass concentration and elemental composition of airborne particulate matter at street and background locations. Atmos Environ 1997;31:1 185-93.

21 Fischer PH, Hoek G, van Reeuwijk H, et al. Traffic-related differences in outdoor and indoor concentrations of particles and volatile organic compounds in Amsterdam. Atmos Environ 2000;34:3713-22.

22 Levy JI, Houseman EA, Spengler JD, et al. Fine particulate matter and polycyclic aromatic hydrocarbon concentration patterns in Roxbury, Massachusetts: a community-based GIS analysis. Environ Health Perspect 2001; 109:341-7

23 Lena TS, Ochieng V, Carter $M$, et al. Elemental carbon and $P M(2.5)$ levels in an urban community heavily impacted by truck traffic. Environ Health Perspect 2002;1 10:1009-15.

24 Jerrett M, Burnett RT, Brook J, et al. Do socioeconomic characteristics modify the short term association between air pollution and mortality? Evidence from a zonal time series in Hamilton, Canada. J Epidemiol Community Health 2004;58:31-40.

25 Krewski D, Burnett RT, Goldberg M, et al. Reanalysis of the Harvard six-cities study and the American Cancer Society study of air pollution and mortality, phase II: sensitivity analysis. Cambridge, MA, Health Effects Institute, 2000.

26 Pope CA III, Burnett RT, Thurston GD, et al. Cardiovascular mortality and longterm exposure to particulate air pollution. Epidemiological evidence of general pathophysiological pathways of disease. Circulation 2004;109:71-7.

27 Seaton A, MacNee W, Donaldson K, et al. Particulate air pollution and acute health effects. Lancet 1995;345:176-8.

28 Peters A, Doring A, Wichmann HE, et al. Increased plasma viscosity during an air pollution episode: a link to mortality? Lancet 1997;349:1582-7.

29 Peters A, Frohlich M, Doring A, et al. Particulate air pollution is associated with an acute phase response in men; results from the MONICA-Augsburg study. Eur Heart J 2001;22:1198-204.

30 Dockery DW, Pope CA, III, Kanner RE, et al. Daily changes in oxygen saturation and pulse rate associated with particulate air pollution and barometric pressure. Res Rep Health Eff Inst 1999;83:1-19.

31 Peters A, Perz S, Doring A, et al. Increases in heart rate during an air pollution episode. Am J Epidemiol 1999; 150:1094-8.

32 Liao D, Creason J, Shy C, et al. Daily variation of particulate air pollution and poor cardiac autonomic control in the elderly. Environ Health Perspect 1999; 107:521-5

33 Pope CA III, Verrier RL, Lovett EG, et al. Heart rate variability associated with particulate air pollution. Am Heart J 1999;138:890-9.

34 Gold DR, Litonjua A, Schwartz J, et al. Ambient pollution and heart rate variability. Circulation 2000;101:1267-73.

35 Peters A, Liu E, Verrier RL, et al. Air pollution and incidence of cardiac arrhythmia. Epidemiology 2000;11:11-17.

36 Statistics Canada. Smoking behaviour of Canadians. Ottawa: Statistics Canada, National Population Health Survey Highlights, 1999. 